\title{
Soil Quality Strengthening - A Way to Achieve Sustainable Crop Intensification- review
}

\author{
D.Dinesh $^{1 *}$, M. Sankar ${ }^{2}$, K. Rajan ${ }^{3}$, Ram A. Jat ${ }^{4}$, Dinesh Jinger ${ }^{5}$ \\ 1,4,5ICAR-Indian Institute of Soil and Water conservation, Research Centre, Vasad, Gujarat \\ ${ }^{2}$ ICAR- Indian Institute of Soil and Water conservation, Dehradun, Uttarakhand \\ ${ }^{3}$ ICAR-Indian Institute of Soil and Water conservation, Research Centre, Udhagamandalam, Tamil Nadu \\ *Corresponding Authors: D.Dinesh, ICAR-Indian Institute of Soil and Water conservation, Research \\ Centre, Vasad, Gujarat
}

\section{INTRODUCTION}

The economical stability and social sustainability of countries, worldwide, depend on their healthy and rich agricultural soils with supportive ecosystems. Agricultural soils have long been regarded merely as a means of holding up the plant and as a result, they have not always been managed properly to maintain and enhance their crop production capability. Many of the technologies and approaches used in food production systems have exploited the natural resources and degraded the environment. Degradation has impaired the socioeconomic wellbeing of people who depend on the land for their sustenance and survival. Decades of excessive soil erosion by both wind and water lead to soil and nutrients depletion and other degradative processes such as acidification, salinization, and compaction and loss of organic matter has resulted due to poor farming practices. This, in turn, has caused a decline in soil quality over large areas and has reduced soil productivity and crop yields in many places. Subsequently, the soil quality has no longer been maintained even with greater levels of technological inputs. Increased sediment and chemical pollution from runoff and deep leaching of fertilizer and pesticides into groundwater are additional concerns.

Principles of soil conservation have known and applied for long back and world nations have developed and implemented national conservation and soil reclamation programmes to help and ensure sustainable food production for future generations. The goals and objectives for soil conservation and management, in policy decisions were targeted at erosion control driven by the relationship between erosion and soil productivity. Yet, past and recent assessments conducted on regional and global scales indicate that these positive interventions by human actions are having only a minimal impact on soil rehabilitation. The fact is that human-induced degradation is still causing the major loss of millions of hectares of land from agricultural production every year. It is now being recognised that erosion control alone is not sufficient to protect soil against the loss of productivity. Other degradative processes including acidification, salinization, compaction, loss of organic matter, and loss of biological activity and diversity must also be controlled. It is also recognized that the cost of soil degradation is greater than simply its effect on agricultural productivity but, must also consider other additional attributes such as soil quality, environmental quality, food safety, and human and animal health. In the past, science and agriculture have largely overlooked or ignored their relationship with soil quality.

\section{The Role of Soil in Environmental Quality and Human Health}

As with air and water, humans and most animal life could not be sustained without the soil because the soil provides their major source of food, however; the soil does far more for society than just producing food. A healthy or good quality soil acts as an environmental filter for cleaning air and water (Fig.1). Soil regulates and partition water flows through the environment by controlling infiltration and the retention and release of water in the soil profile and below the rooting zone. Soils can store almost the level of carbon stock than the atmosphere, if managed properly is a major sink for 
global gases and can favourably affect the atmospheric carbon dioxide balance by offsetting emissions from the burning of fossil fuels. Soil is the ultimate receptor and incubation chamber for the detoxification, decomposition, and humification of organic wastes and recycling of nutrients from these materials back to plants. Soil degradation induced by erosion represents a major threat to food production and ecosystem service globally. (Sankar, et al, 2018). Soil can pollute air and water if mismanaged, and in some instances, these adverse impacts may be more important to society than the effects of soil degradation on agricultural productivity. There is a strong linkage among health and quality of the soil, nutritional quality of food, and human health. Well, being and prosperity of people whose lives depend on the food produced by soils. Lal, (2009) said that Soil degradation affects human nutrition and health through its adverse impacts on the quantity and quality of food production. The decline in crops' yields and agronomic production aggravates food-insecurity that currently affects 854 million people globally, and low concentration of protein and micronutrients (e.g., $\mathrm{Zn}, \mathrm{Fe}$, Se, B, I) aggravate malnutrition and hidden hunger that affects 3.7 billion people, especially children.

Deckelbaum et al. (2006) Econutrition integrates environmental health and human health, with a particular focus on the interactions among the fields of agriculture, ecology, and human nutrition. Soil loss and degradation and human undernutrition are major barriers to economic development in developing countries.

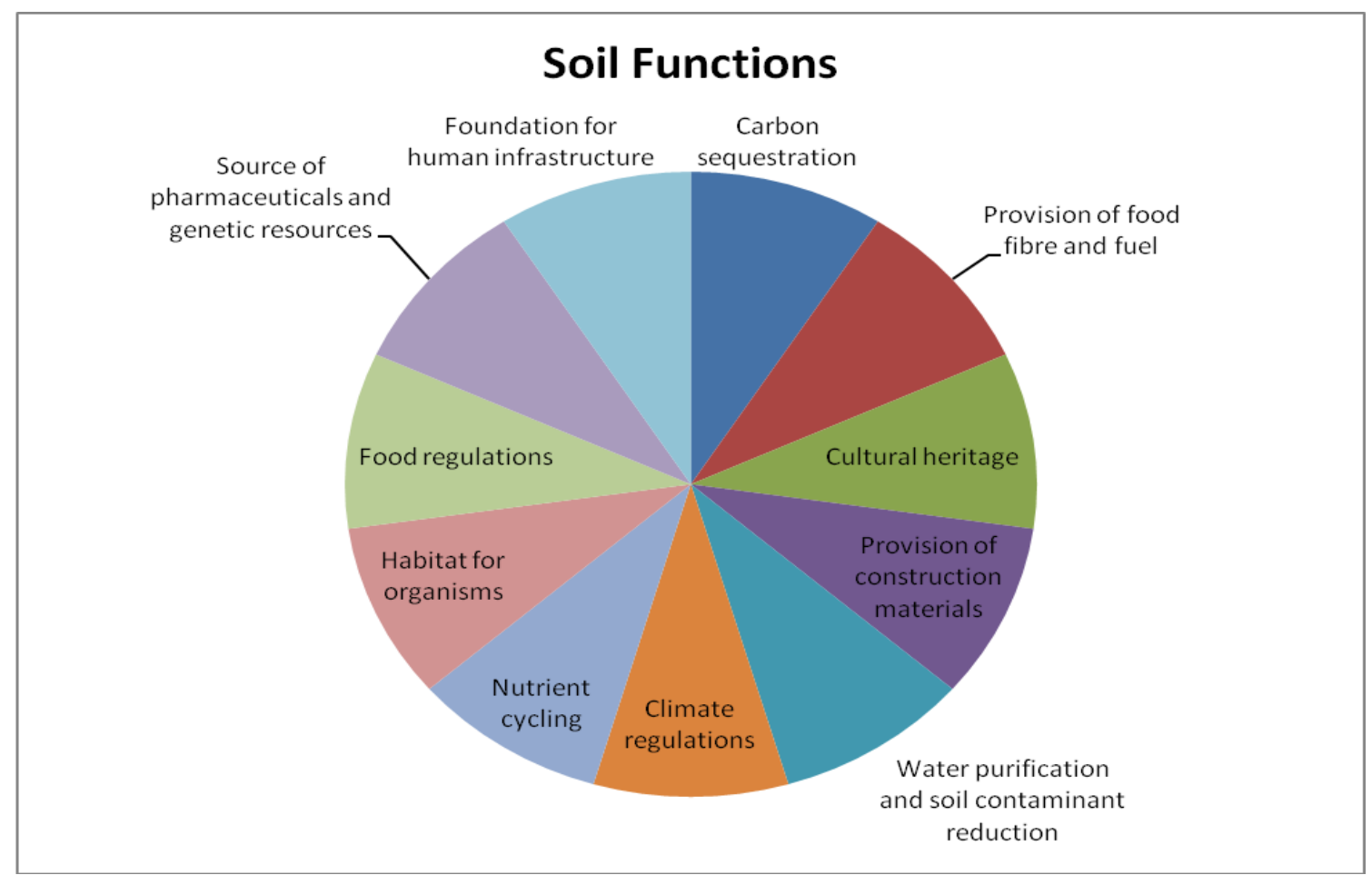

Fig1. Soil Functions -Soils deliver ecosystem services that enable life on earth

Source http://www.fao.org/soils-2015/en/;

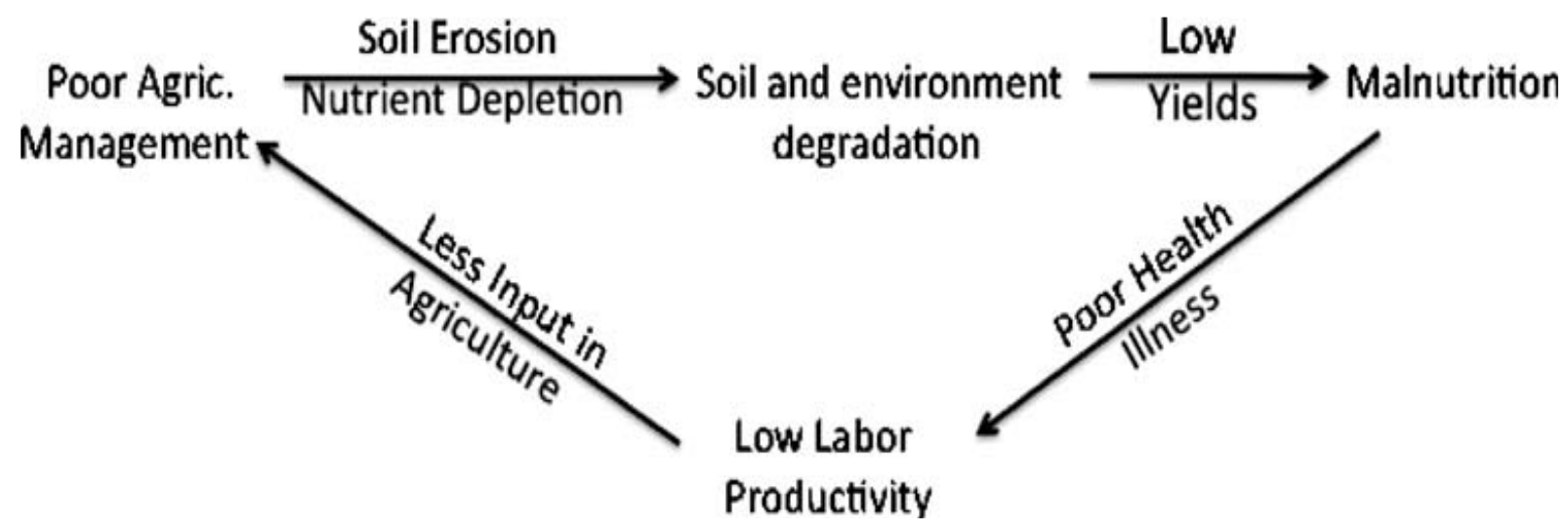


Fig2. Link between soil degradation and human health (modified from Deckelbaum et al. 2006)

\section{The CONCEPT OF SOIL QUALiTY}

Soil quality is a new concept which describes its capacity to perform three major functions, productivity enhancement, environmental protection, and health (Parr et al., 1992). Though several definition of soil quality exist one that appears to receive general acceptance and includes these three functions is the capability of a soil to produce safe and nutritious crops in a sustained manner over the long term and to enhance human the environment. This definition recognizes that the functions of soil performs in agroecosystems go beyond those of traditional crop production and that the term soil quality is not synonymous with that of soil productivity which has been historically the case. Soil quality subject to change with land uses and varies over time because of continues change and variation in its properties (Karlen et al., 2003). Optimum qualities of physical, chemical, and biological properties of soil are critical to maintaining the optimum fertility (Schoenholtz et al., 2000). Soil quality can also be defined as the capacity of a specific kind of soil to function, within natural or managed ecosystem boundaries, to sustain plant and animal productivity, maintain or enhance water and air quality, and support human health and habitation.

The need to broaden the definition of soil quality to include these three functions or attributes have been highlighted by many soils scientists worldwide. The attributes of soil quality should not be limited to the issues of soil productivity per se, but should also include on an equal basis, environment quality, human and animal health, and food safety and quality. The soil scientist's proposed that a minimum data set be developed to indentify scientifically valid criteria for soil quality assessment and monitoring. The development of a soil quality index was also suggested as a means to help identify problems in production areas and make a realistic estimate of world food prospects, provide information for predicting the effects of global climate change, and stimulate governments to formulate realistic agricultural policies and allocate scarce soil resource wisely.

\section{COMPONENTS OF SOIL QUALITY}

The soil quality as discussed above is a composite of the individual capacities of the soil to perform productivity, environmental and health functions. Thus a set of indicators or attributes of soil quality should serve as a measure of how well the soil can perform these functions as well as respond to change in management practices.

\section{Productivity}

The soil function that is best understood in terms of science and application is crop productivity. Most soil science textbooks and related literature treat soils and soil management from the standpoint of maximising the productivity for use of the soil to produce crops. Soil attributes important to productivity are those that influence the physical, chemical and biological properties of soils. Plants species vary in their soil requirements for optimum growth conditions. (e.g. soil depth, texture, $\mathrm{pH}$, fertility, etc.,) thus across a range of crops, the attributes needed to optimize the productivity may be similar but may differ in degree. Soil properties and conditions at or near the soil surface which are important for crop production can be improved through cultural and management practices with varying success.

\section{ENVIRONMENT}

The soil quality component that relates to the environmental function is less understood than that of productivity. Baer et al., (2012) Ecosystem services benefit human welfare through supporting or regulatory functions. Conservation based soil management provides food, fuel and fiber; controls erosion; infiltrates water; abates nutrients; regulates greenhouse gases; and reduces agricultural pests, recycling, decomposition and humification of organic amendments and sequestration of carbon. Abundant and diverse belowground biota influence all of the ecosystem services provided by soil. Others may include the capability of the soil to detoxify organic wastes through bioremediation and to serve as a receptor for the decomposition of human wastes such as sewage and garbage and the return of nutrients and carbon back into soil constituents

\section{HeAlth}

Least understood is the soil quality component that relates to the human and animal health and food safety functions. There is some evidence in the literature that suggests that soil quality can affect the nutritional quality of food produced on certain soils; however, the relationship is usually not well 
understood. The presence of heavy metals or toxic organics in the soil with high bioavailability or excessive nitrates may not impair the soil productivity or environmental functions but could result in low food quality or food unfit for human and animal consumption. Soil qualities are known to directly or indirectly affect the nutritional quality of crops include $\mathrm{pH}$, available nutrients, texture, organic matter content, and soil water relationships. However, the type of response of soil quality on food quality maybe modified by crop and variety, type of fertilizer management practices and handling and storage conditions

\section{SoIl QUALITY ANd SUSTAINABle Crop INTENSIFICATIONS}

Sustainable crop intensification includes a number of attributes that may be weighted differently depending on their importance in a locale or region. These include the issues of profitability; productivity; soil, water and air quality; energy efficiency; fish and wildlife habitat; quality of life; and social and cultural acceptance. Regardless of various factors and their weightage, soil quality must be maintained or improved and it is regarded as a key indicator of sustainable crop intensification.

It is important that the attributes used to monitor changes in soil quality in response to changes in farming practices are (1) sensitive enough for the time period in question, and (2) accurately reflect the net of positive and negative influences of soil management over time. It is also important to know and understand the process by which the components of a management system affect soil quality and sustainability. This type of information is required for designing soil management systems that will improve soil quality. The scientific research organisation of the national academy of science, in their recent report on soil and water quality under the agenda for agriculture, recommends that our national policy should seek to conserve and enhance soil quality as a fundamental first step to environmental improvement. The report emphasizes that the first step in controlling water and air pollution should be through the improvement of soil quality. Thus, improving soil quality maybe the most effective approach for responding to society's criticism of present-day production agriculture for failing to meet sustainability goals.

The best means of improving or maintaining soil quality are alternative agriculture practices such as crop rotations, reduced tillage, recycling of crop residues and animal manures, optimised use of chemical fertilizers and pesticides and increased use of cover crops and green manure crops, including nitrogen-fixing legumes. All of these practices tend to enhance beneficial soil biological activity and diversity and in turn to increase the soil organic matter content and nutrient availability and the resistance of the soil to erosion and nutrient runoff.

Parr et al. (1992) presented a conceptual diagram of how the various attributes of soil quality are linked with strategies of alternative agriculture and the goals of sustainable crop intensification.

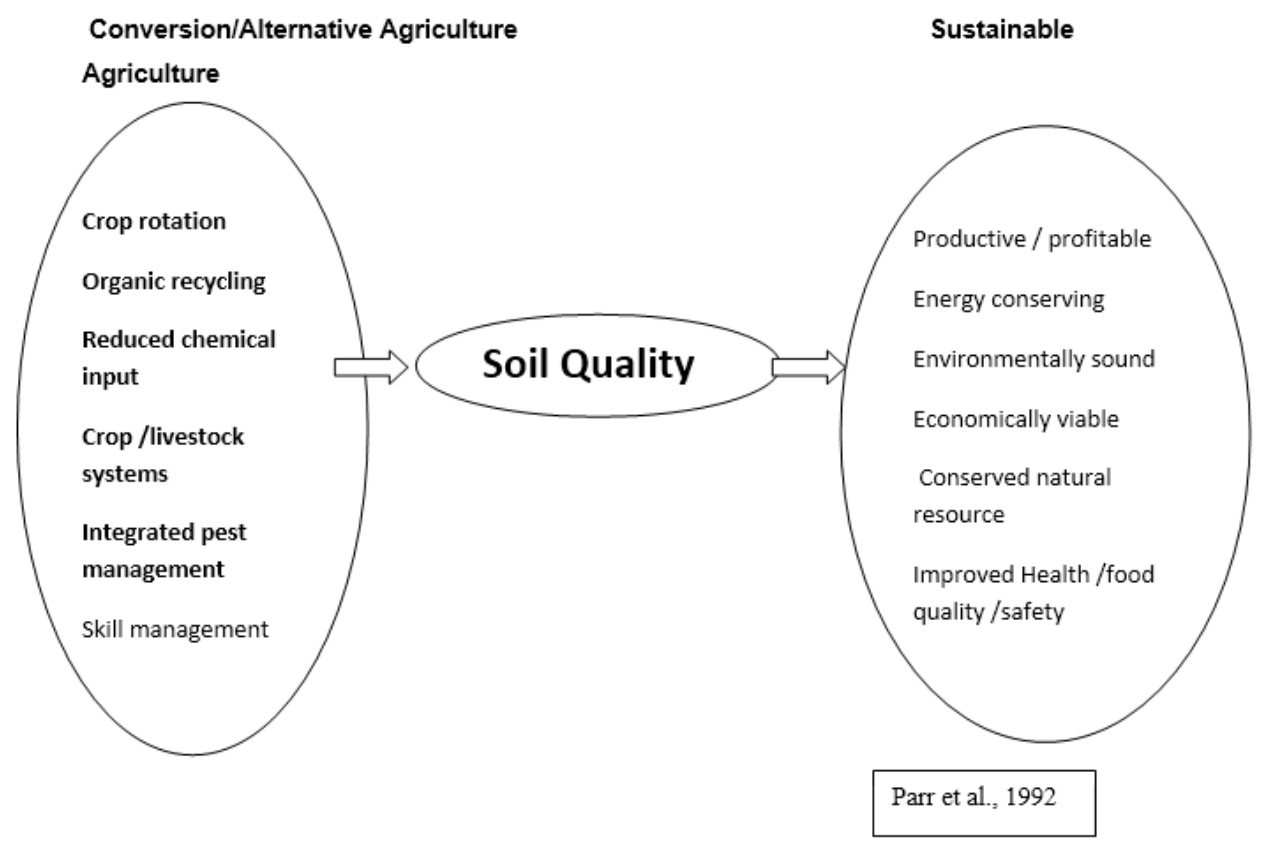


Fig3. Highlight that soil quality occupies a pivotal position in these relationship demonstrating that it is a vital linkage to a more sustainable agriculture.

\section{REFERENCES}

[1] Baer S, Heneghan L, Eviner V. Applying Soil Ecological Knowledge to Restore Ecosystem Services. In: Wall DH, editor. Soil Ecology and Ecosystem Services. United Kingdom: Oxford University Press eds; 2012.

[2] Deckelbaum, R. J., Palm, C., Mutuo, P., \& DeClerck, F. (2006). Econutrition: Implementation Models from the Millennium Villages Project in Africa. Food and Nutrition Bulletin, 27(4), 335-342. https://doi.org/10.1177/156482650602700408

[3] Karlen, D.L., Ditzler, C.A. and Andrews, S.S., 2003. Soil quality: why and how? Geoderma, 114(3-4), pp.145-156.

[4] Lal, R. Restoring Soil Quality to Mitigate Soil Degradation. Sustainability 2015, 7, 5875-5895.

[5] Lal, R. Soil degradation as a reason for inadequate human nutrition. Food Sec. 1, $45-57$ (2009). https://doi.org/10.1007/s12571-009-0009-z

[6] Parr, J., Papendick, R., Hornick, S., \& Meyer, R. (1992). Soil quality: Attributes and relationship to alternative and sustainable agriculture. American Journal of Alternative Agriculture, 7(1-2), 5-11. doi:10.1017/S0889189300004367

[7] Sankar, M. et al., Nationwide soil erosion assessment in India using radioisotope tracers $137 \mathrm{Cs}$ and $210 \mathrm{~Pb}$ : the need for fallout mapping. Curr. Sci., 2018, 115(3), 388-390.

[8] Schoenholtz, S.H., Van Miegroet, H. and Burger, J.A., 2000. A review of chemical and physical properties as indicators of forest soil quality: challenges and opportunities. Forest ecology and management, 138 (13), pp.335-356.

Citation: D.Dinesh, et.al., Soil Quality Strengthening - A Way to Achieve Sustainable Crop Intensificationreview” International Journal of Research Studies in Agricultural Sciences (IJRSAS), 2020; 6(8), pp. 29-33, https://doi.org/10.20431/2454-6224.0608005

Copyright: () 2020 Authors. This is an open-access article distributed under the terms of the Creative Commons Attribution License, which permits unrestricted use, distribution, and reproduction in any medium, provided the original author and source are credited. 